University of Nebraska - Lincoln

DigitalCommons@University of Nebraska - Lincoln

1991

\title{
Predicting Canopy Light-Use Efficiency from Leaf Characteristics
}

T. J. Arkebauer

University of Nebraska-Lincoln, tarkebauer1@unl.edu

Follow this and additional works at: https://digitalcommons.unl.edu/natrespapers

Part of the Natural Resources and Conservation Commons, Natural Resources Management and Policy Commons, and the Other Environmental Sciences Commons

Arkebauer, T. J., "Predicting Canopy Light-Use Efficiency from Leaf Characteristics" (1991). Papers in Natural Resources. 1181.

https://digitalcommons.unl.edu/natrespapers/1181

This Article is brought to you for free and open access by the Natural Resources, School of at DigitalCommons@University of Nebraska - Lincoln. It has been accepted for inclusion in Papers in Natural Resources by an authorized administrator of DigitalCommons@University of Nebraska - Lincoln. 


\title{
Predicting Canopy Light-Use Efficiency from Leaf Characteristics
}

\author{
J. M. NORMAN \\ University of Wisconsin \\ Madison, Wisconsin \\ T. J. ARKEBAUER \\ University of Nebraska \\ Lincoln, Nebraska
}

Reference\#1275

Vegetation depends on light energy from the sun to convert $\mathrm{CO}_{2}$ from the air to essential life-sustaining carbon compounds. Light has long been recognized as an essential factor in photosynthesis, which provides biochemical energy and carbon necessary for plant growth. The light-gathering system consists mainly of an aerial array of leaves, with a light trapping effectiveness that depends on many plant and environmental factors. The operation of this light-gathering system is a key determinant of plant productivity. A clearer understanding of it will help us to predict the growth of crops with more reliability.

The accumulated growth of any plant depends on the total carbon fixed by photosynthesis and the fraction of that carbon that can be converted to dry matter (DM). Although nutrients other than carbon also are essential to tissue growth, this chapter will consider only carbon. Only a portion of carbon fixed by photosynthesis eventually appears as standing DM. Some of the carbon is lost through plant respiration in two ways: (i) synthesis of compounds that form the final DM; and (ii) maintenance of the living complex in a functioning condition. These two forms of respiration are usually referred to as growth and maintenance. The distinction between them is somewhat arbitrary, so separation of the two components is difficult experimentally.

A simplistic view of the disposition of carbon in a growing plant can be considered as a combination of three processes: (i) photosynthetic carbon fixation; (ii) maintenance respiration; and (iii) growth respiration. Although considerable uncertainty exists in the knowledge of all three processes, the work of Penning deVries et al. (1974) has increased our confidence in growth respiration estimates so that carbon fixation and maintenance respiration represent greater uncertainty.

In this chapter, we will consider photosynthetic carbon fixation and its efficiency in terms of the mass of $\mathrm{CO}_{2}$ fixed per unit of absorbed photosyn-

Copyright ( 1991 ASA-CSSA-SSSA, 677 S. Segoe Rd., Madison, WI 53711, USA. Modeling Plant and Soil Systems-Agronomy Monograph no. 31. 
thetically active radiation; called the photosynthetic light-use efficiency $\left(\mathrm{LUE}_{\mathrm{p}}\right)$. Alternatively, the mass of DM produced per unit of absorbed photosynthetically active radiation (PAR) could be termed the dry matter lightuse efficiency $\left(\mathrm{LUE}_{\mathrm{dm}}\right)$. Clearly, $\mathrm{LUE}_{\mathrm{dm}}$ involves maintenance and growth respiration, which may not depend on light directly, and photosynthesis, which does depend on light interception directly.

The concept of a relatively constant $\mathrm{LUE}_{\mathrm{dm}}$ has great potential for simplifying the prediction of plant productivity. Since incoming solar radiation (SR) or PAR are relatively easy to measure, the simple product of intercepted or absorbed PAR and the appropriate canopy LUE $_{\mathrm{dm}}$ could provide an estimate of DM increment. This concept was used by Monteith (1977) to study the effect of climate on crop production in Britain. Monteith's approach was expanded by Charles-Edwards (1981), who carried out a very similar analysis. Numerous investigators have used this approach and measured the canopy LUE $_{\mathrm{dm}}$ for various crops. Monteith (1977) suggested a seasonal canopy LUE $_{\mathrm{dm}}$ value of $1.4 \mathrm{~g} \mathrm{DM}\left(\mathrm{MJ}\right.$ ISR) ${ }^{-1}$ (ISR represents intercepted solar radiation) based on above-ground data from apple (Pyrus L.) barley (Hordeum L.), sugar beet [Beta vulgaris (L.) var. Cicla], and potato (Solanum tuberosum L.). Gallagher and Biscoe (1978) found a seasonal value of $3.0 \mathrm{~g} \mathrm{DM(MJ}$ APAR) $^{-1}$ (APAR represents absorbed PAR) for wheat (Triticum aestivum L.) and barley in Britain, including roots and tops. This is approximately equivalent to the value used by Monteith (1981) of $4.3 \mathrm{~g} \mathrm{CO}_{2}$ (MJ ISR) $^{-1}$, as well as the value of $1.4 \mathrm{~g}$ DM (MJ ISR) ${ }^{-1}$ reported by Monteith (1977). Unsworth et al. (1984) measured a value of about $1.2 \mathrm{~g} \mathrm{DM(MJ} \mathrm{ISR)}{ }^{-1}$ on soybean [Glycine $\max (\mathrm{L}$.$) Merr.] at various moderate levels of ozone treat-$ ment. Muchow and Coates (1987) determined seasonal sorghum LUE between 2.1 and $2.4 \mathrm{~g} \mathrm{DM(MJ} \mathrm{IPAR})^{-1}$ for intercepted PAR on a seasonally integrated basis. Charles-Edwards (1981) has summarized some values of canopy LUE from the literature and simply reported them as $\mathrm{g} \mathrm{DM} \mathrm{MJ}^{-1}$ : Rice (Oryza sativa L.), 4.2; corn (Zea mays L.), 3.4; sweet potato (Ipomoea batatas Lam.), 3.1; kale (Brassica oleracea var. Accephala), 2.7; sunflower (Helianthus annuus L.), 2.6; cotton (Gossypium hirsutum L.), 2.5; clover, 1.6; and soybean, 1.3. Unfortunately these values are difficult to interpret since the form of the radiation (solar or PAR) is not indicated.

The values of LUE reported in the literature vary by more than a factor of three. Either LUE is not very constant across crops, and thus of more limited usefulness than we might desire, or the values reported do not have a common basis. In fact both of these conditions may apply. The main objective of this chapter is to investigate the basis for a canopy LUE and relate various ways of expressing the numerical values.

\section{CANOPY LIGHT-USE EFFICIENCY DEFINITIONS}

Throughout the literature many definitions are used for canopy LUE; no standard form is apparent. A definition of canopy LUE involves three aspects: (i) the time interval involved-instantaneous, hourly, daily, weekly, or seasonal; (ii) the form of the carbon-dry matter above ground 
(DMAG), total plant dry matter including roots (DMT), or net $\mathrm{CO}_{2}$ uptake by the plant top $\left(\mathrm{CO}_{2}\right)$; and (iii) characterization of the radiation-solar radiation intercepted (ISR) or absorbed (ASR), or photosynthetically active radiation intercepted (IPAR) or absorbed (APAR). Intercepted radiation is ( $\mathrm{I}$ in $\mathrm{MJ} \mathrm{m}{ }^{-2}$ ) the radiation transmitted $\left(\mathrm{T}\right.$ in $\mathrm{MJ} \mathrm{m}{ }^{-2}$ ) to the bottom of the canopy subtracted from the incident radiation.

$$
\mathrm{IPAR}=I-T
$$

Absorbed radiation is the difference between net radiation (PAR or SR) above the canopy (downward $[I]$ minus upward $[R C]$ ) and the net radiation below the canopy (radiation transmitted [ $T$ ] minus radiation reflected from the soil [RS]).

$$
\operatorname{APAR}=(I-\mathrm{RC})-(T-\mathrm{RS})
$$

The units in Eq. [1] and [2] are $\mathrm{MJ} \mathrm{m}^{-2}$ in the appropriate wave band (PAR or SR). In the PAR waveband, $1 \mathrm{MJ} \mathrm{m}^{-2}$ is $4.6 \mathrm{~mol}$ photon $\mathrm{m}^{-2} \mathrm{~s}^{-1}$ if the sun is the source of radiation.

The form of the fixed carbon affects the numerical values of canopy LUE. The conversion between $\mathrm{g} \mathrm{CO}_{2}$ and $\mathrm{g}$ DM depends on the composition of the plant because the amount of carbon required to build carbohydrates, proteins, and lipids is different. Furthermore, the amount of these constituents in various plants is different. Appropriate conversion factors can be obtained from Penning deVries et al. (1974) or McDermitt and Loomis (1981). When DM is used to express the carbon fixed, the roots are included only some of the time. Since the fraction of the total plant DM that is in roots may vary from $10 \%$ for some agronomic crops to $80 \%$ for some native prairie grasses, this is not a minor inconsistency. In addition, roots may lose significant amounts of carbon by sloughing, exudation, and respiration. Furthermore, with annuals, the amount of DM standing is known to be derived from carbon fixed in a given growing season. With perennials, the standing biomass may have been accumulated over several years and the contribution of a given season is difficult to quantify; especially if roots are a major component of carry-over between growing seasons. These uncertainties in respiration and root losses make it essential to obtain good estimates of the carbon fixed by photosynthesis if we are to advance our knowledge of the carbon budget.

Muchow and Coates (1987) discuss the likely effect of including root DM and intercepted vs. absorbed solar and photosynthetically active radiation in cereals. The various definitions of LUE can result in numerical values that differ by more than a factor of two for a given canopy and condition. This chapter contains a discussion of LUE and some interpretation of the concept.

\section{MODEL DESCRIPTIONS}

This chapter describes the photosynthetic and respiration response functions of individual leaves in various parts of a canopy and then integrates 
their various contributions to obtain the canopy net photosynthetic rate over some appropriate time interval. This approach requires that we first describe the dependence of leaf photosynthesis and respiration on various factors, such as light, temperature, water status, leaf spectral properties, and position in the canopy. Canopy carbon exchange rates are estimated from a model titled Cupid by combining the equations that describe leaf carbon exchange rates with a characterization of canopy architecture and incident radiation above the canopy. A description of canopy architecture includes the vertical distribution of stem and leaf area, leaf angle distributions, canopy height, and the horizontal distribution of foliage, such as random or clumped. Estimates of canopy photosynthetic LUE can be obtained from Cupid using various definitions.

The stand DM LUE can be obtained by combining the carbon fixed in photosynthesis with estimates of growth and maintenance respiration.

\section{A. Leaf Model}

The model that we use to predict leaf net photosynthetic rate is based on the work of von Caemmerer and Farquhar (1981). The leaf model equations used here are very similar to CULEAF, which is described with program listing in Norman (1986), except that the equation for describing the dependence of assimilation rate on temperature was obtained from Schoolfield et al. (1981). The basis of this model is the relation between net assimilation rate $\left(\mathrm{A}, \mu \mathrm{mol} \mathrm{m} \mathrm{m}^{-2} \mathrm{~s}^{-1}\right)$ and internal $\mathrm{CO}_{2}$ concentration $\left(\mathrm{C}_{\mathrm{i}}, \mu \mathrm{mol}\right.$ $\mathrm{mol}^{-1}$ ). Von Caemmerer and Farquhar (1981) describe how $\mathrm{C}_{\mathrm{i}}$ is calculated. The strength of this approach is that limitations to $\mathrm{CO}_{2}$ uptake that occur in the diffusion path (primarily stomata) can be distinguished from limitations caused by the biochemistry of photosynthesis. Example data for A vs. $\mathrm{C}_{\mathrm{i}}$ for soybean (C3) and sorghum [Sorghum bicolor (L.) Moench] (C4) leaves, which were obtained in the field under a range of incident light conditions, are given in Fig. 7-1. The leaf photosynthesis submodel of the Cupid model requires mathematical equations that capture the essential characteristics of the dependence of leaf assimilation rate on all the major environmental factors. Not only is incident light important, as shown in Fig. 7-1, but effects of leaf temperature, air vapor pressure, and plant water status are important as well. Measurements of these leaf responses on plants grown in controlled environments are usually not appropriate for estimating canopy photosynthesis of field-grown crops. Therefore, leaf gas-exchange measurements are made in the field with portable gas-exchange instruments.

The leaf response functions for photosynthesis, which are used in this paper, are typical of C4 (corn or sorghum) and C3 crops (soybean or wheat), and are shown in Fig. 7-2. The dependence of assimilation rates on internal $\mathrm{CO}_{2}$ concentration and light from this model are shown in Fig. 7-2a for corn. Since the von Caemmerer and Farquhar (1981) leaf photosynthesis model is appropriate for $\mathrm{C} 3$ plants, the parameter values cannot be interpreted in the same way for a C4 plant. However, the parameters of the von Caemmerer and Farquhar (1981) model were adjusted to fit corn photosyn- 


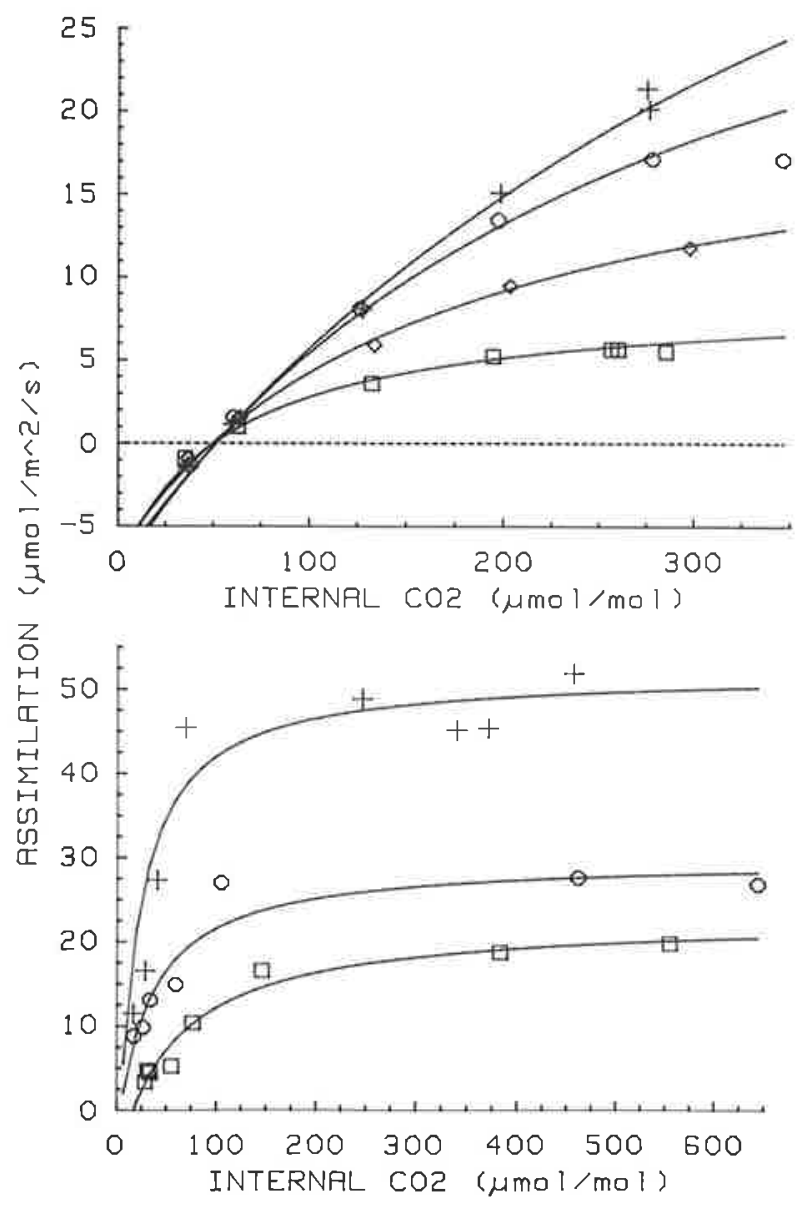

Fig. 7-1. The measured dependence of photosynthetic rate on internal $\mathrm{CO}_{2}$ concentration for sorghum and soybean for a range of photosynthetically active radiation flux densities. In the upper graph (soybean), the symbols represent the following: $+1000,0430, \diamond 220$, and $\square 120 \mu \mathrm{mol}$ photons $\mathrm{m}^{-2} \mathrm{~s}^{-1}$. In the lower graph (sorghum), the symbols represent the following: +1900 , $\circ 900$, and $\square 400 \mu \mathrm{mol}$ photons $\mathrm{m}^{-2} \mathrm{~s}^{-1}$.

thetic and respiratory responses based on our own field measurements and those of Chmora and Oya (1967), Edmeades and Daynard (1979), and Vietor et al. (1977). Figure 7-2b contains a light-photosynthesis response for upper sunlit leaves of $\mathrm{C} 3$ and $\mathrm{C} 4$ crop types. The $\mathrm{C} 3$ parameters are essentially those of von Caemmerer and Farquhar (1981), except for the temperature response mentioned earlier in this section. Also, the maximum rate of electron transfer was increased over the value they used, so maximum rates of photosynthesis in full sunlight are about $50 \%$ greater.

The variation of leaf photosynthetic characteristics with depth in the canopy is an important factor to consider in the prediction of canopy photosynthesis from leaf photosynthesis, and enters into the Cupid model through 

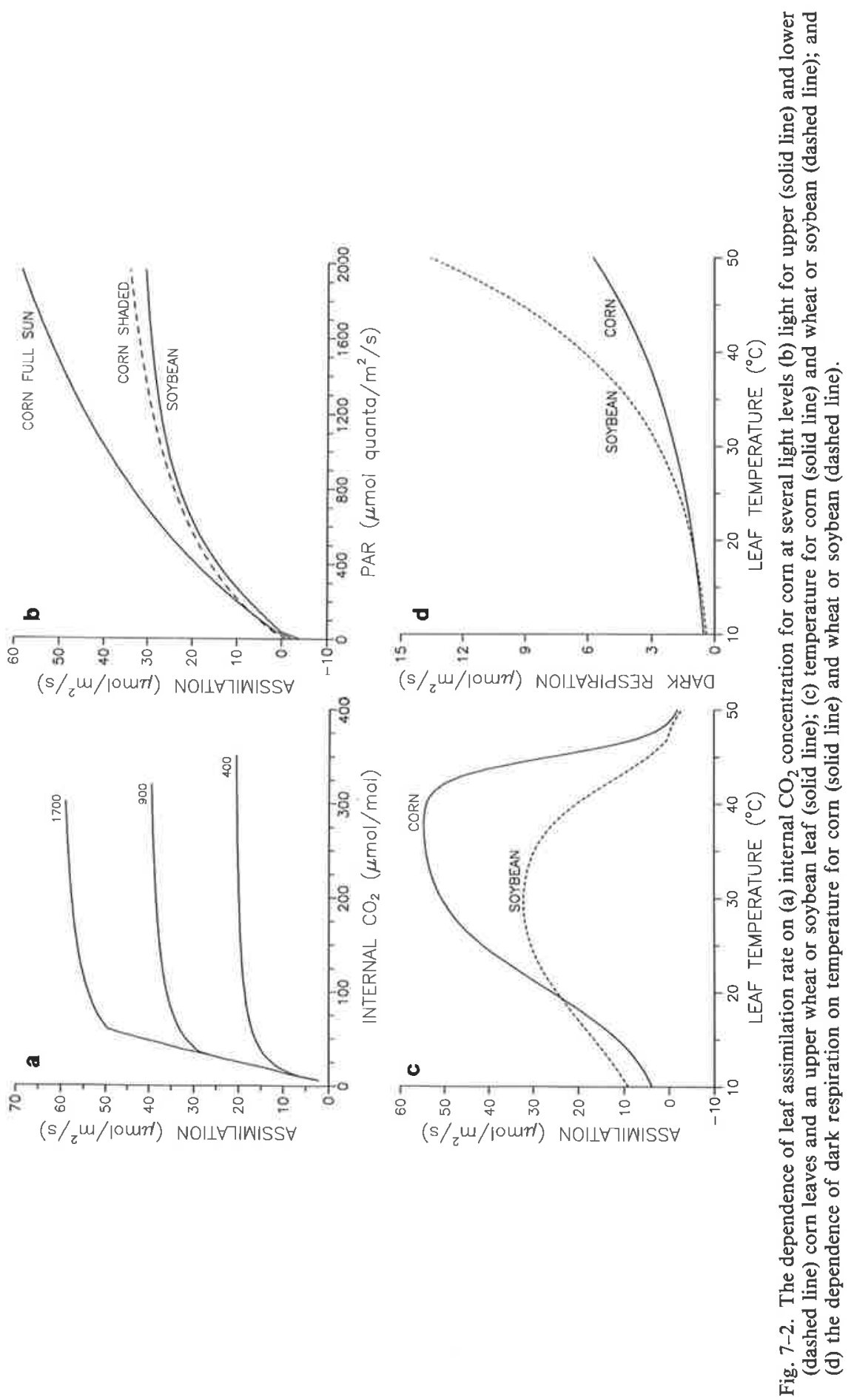
the effects on a leaf's previous light history. The effect of the previous light history of a leaf, which affects the maximum electron transfer rate in full sunlight, the maximum rate of carboxylation and dark respiration, is related to the leaf area index above the particular leaf. Leaves lower in the canopy are less productive when exposed to the sun and more productive in the shade than the uppermost leaves (Fig. 7-2b). Typical leaf photosynthetic rate dependence on temperature is shown in Fig. $7-2 c$ for $\mathrm{C} 4$ and $\mathrm{C} 3$ plants. This type of response curve is difficult to obtain and probably changes as a plant adapts to varying temperature environments (deWit, 1978). Measurements taken by Chmora and Oya (1967) on corn indicate moderate leaf photosynthetic rates at leaf temperatures above $50^{\circ} \mathrm{C}$. This is higher than upper limits measured in the field in Nebraska, but high temperature and leaf water stress are difficult to separate under field conditions. The simulations done for this chapter did not result in leaf temperatures above $35^{\circ} \mathrm{C}$, so uncertainties in the temperature curve above $40^{\circ} \mathrm{C}$ do not affect these results. Curves such as those shown in Fig. 7-2c are difficult to take too seriously for predicting canopy photosynthesis from leaf photosynthesis. The curves may even vary with time of day (Chmora \& Oya, 1967). They typically are obtained for a single leaf that will be experiencing a different temperature than the other nonenclosed leaves on the plant. Such leaves tend to show a more marked temperature dependence because of exposure to conditions that they have not had time to adapt to. deWit (1978) recognized this and, as part of his corn model, assumed that corn photosynthetic rate was independent of leaf temperature above $13{ }^{\circ} \mathrm{C}$ and linearly decreased to zero between 13 and $8{ }^{\circ} \mathrm{C}$. This response is quite different from those of Chmora and Oya (1967) and Fig. 7-2c. In this chapter, we predict canopy LUE using the temperature dependence in Fig. 7-2c and compare LUE with the results that we obtain by assuming the photosynthetic response to temperature, similar to the method used by deWit (1978).

Stomatal conductance is calculated from leaf photosynthesis, leaf-toair vapor pressure deficit, and leaf water potential by a method similar to Norman (1986). An unstressed stomatal conductance is calculated from the leaf photosynthetic rate (from the von Caemmerer \& Farquhar [1981] model) by assuming $C_{i} / C_{a}$ is constant. This ratio is known to vary by species and genotype, but we use 0.4 for $\mathrm{C} 4$ crops and 0.72 for $\mathrm{C} 3$ crops in this study. High leaf-to-air vapor pressure deficits and low leaf water potentials can result in stomatal closure. Leaf water potential does not result in stomatal closure because all simulations in this chapter are done with adequate soil moisture. The dependence of stomatal conductance on vapor-pressure deficit is controversial for agricultural crops because its magnitude may depend on growing conditions. Controlled-environment-grown plants tend to have a greater dependence on vapor pressure deficit than field grown plants. The complications associated with predicting the effect of vapor pressure deficit on stomatal conductance are formidable (Losch \& Tenhunen, 1981; Schulze et al., 1987). Because of this uncertainty, $C_{i} / C_{a}$ values listed above were chosen based on midday measurements from corn and soybean leaves when the vapor pressure deficit was approximately 2 to $3 \mathrm{kPa}$. Choosing $\mathrm{C}_{\mathrm{i}} / \mathrm{C}_{\mathrm{a}}$ in this way 
implicitly incorporates a vapor pressure deficit effect in the estimation of stomatal conductance from photosynthesis, and accomplishes reasonable agreement between predicted and measured conductances. A clever approach has been suggested by Ball et al. (1986), but it remains to be determined whether it reduces uncertainty in stomatal conductance prediction under field conditions.

The leaf dark respiration rate also depends on temperature and, in this study, we assume a rate of $2.0 \mu \mathrm{mol} \mathrm{m}^{-2} \mathrm{~s}^{-1}$ at $25^{\circ} \mathrm{C}$ for corn or sorghum with a $\mathrm{Q}_{10}$ of about 1.8 , and $1.1 \mu \mathrm{mol} \mathrm{m}^{-2} \mathrm{~s}^{-1}$ at $25^{\circ} \mathrm{C}$ for soybean or wheat (Fig. 7-2d).

Leaf reflectance and transmittance are characteristics that are essential for the prediction of radiation interception or absorption. Since LUE has been expressed in terms of both SR and PAR, we will consider radiation extinction for both these wavelength bands. This is best accomplished by obtaining leaf spectral properties in visible and near-infrared (NIR) wavelength bands, and solving the extinction and scattering equations separately for each of these bands. The light extinction distributions in the PAR are used directly for predicting photosynthesis and stomatal conductance of leaves and the canopy. The radiation penetration results from the PAR and NIR wavelength bands are added together to obtain the ASR or ISR for energy balance considerations. Table 7-1 contains some leaf spectral properties measured in the field on intact plants (Walter-Shea, 1987).

\section{B. Canopy Model}

The collective effect of all the leaves must be obtained to predict the canopy light use. The light, temperature, humidity, and wind environments appropriate for each leaf are obtained from a combined solution of the leaf energy budget for leaves in various angle classes and layers, and vertical profile equations for radiation and turbulent transfer (Norman, 1979; Norman \& Campbell, 1983). An iterative solution technique is used to solve the combination of vertical profile equations for convective exchange (Norman \& Campbell, 1983) and the leaf energy budget equations (Norman, 1979). The fluxes of $\mathrm{CO}_{2}$, water vapor, energy, and radiation from leaves in various leaf angle classes are totaled to obtain the layer source or sink necessary for the solution of the vertical profile equations. The temperature, humidity, light, and wind from the solution to the vertical profile equations are necessary to the solution of the leaf energy budget equations. Of course, solution of a leaf energy budget equation requires a stomatal conductance for each angle class. Because photosynthetic rate is required to calculate stomatal conductance, the Farquhar-von Caemmerer (1982) model becomes a part of this iteration loop.

This methodology incorporates aerodynamic resistances above and within the canopy, and boundary layer resistances of individual leaves. Because of these additional resistances in the leaf-to-atmosphere water vapor path, stomatal conductance may exhibit minor control over transpiration until severe closure occurs, especially in canopies shorter than 1 or $2 \mathrm{~m}$. 
Table 7-1. Leaf reflectance and transmittance for corn and soybean in visible (PAR) and near-infrared (NIR) wavelength bands from field measurements on intact plants using an integrating sphere.

\begin{tabular}{lccrcrr}
\hline & \multicolumn{2}{c}{ Leaf reflectance } & & \multicolumn{2}{c}{ Leaf transmittance } \\
\cline { 2 - 3 } \cline { 5 - 6 } & & & PAR & NIR \\
\cline { 2 - 3 } \cline { 5 - 6 } & & NIR & & & & \\
Corn & 9 & 38 & & 4 & 45 \\
Soybean & 9 & 42 & & 4 & 42 \\
\hline
\end{tabular}

The Cupid model, which is used for the simulations reported in this chapter, incorporates many plant, atmospheric, and soil processes with considerable detail in an attempt to provide a defendable integration from the leaf level to the canopy level (Norman, 1979, 1986; Norman \& Campbell, 1983). However, some processes that may affect canopy LUE have not been considered. For example, the fraction of light absorbed by leaves may depend on the incidence angle of the direct beam on the leaf (Walter-Shea, 1987). Because the model does not account for the dependence of light absorption on incident angle, it may slightly overestimate photosynthesis of some leaves. We also have ignored the fluctuating light conditions within the canopy. High frequency light fluctuations from wind effects may increase photosynthetic rates and low frequency fluctuations from sun angle shifts may decrease photosynthetic rates because of stomatal and photosynthetic-induction delays. Furthermore, direct effects of wind on stomata and the leaf angle distribution have not been considered, nor have effects of leaf movement. In fact, the only leaf angle distribution used for these simulations is the spherical distribution, which is reasonable for corn and vegetative stages of soybean growth.

The radiation extinction equations described by Norman (1979), which are used for random leaf positioning, can be modified for the clumping effect of rows by using the clumping factor defined by Nilson (1971). This effect improves light interception estimates for canopies of partial cover, but appears to be minor in crops such as corn or soybean as full cover is approached.

\section{Respiration Considerations}

The instantaneous net $\mathrm{CO}_{2}$ taken up by a plant is the difference between $\mathrm{CO}_{2}$ fixed by photosynthesis and that respired by growth and maintenance respiration processes. The net photosynthetic rate measured with leaf chambers in the field provides us with an estimate of the net $\mathrm{CO}_{2}$ exchange for leaves. However, other organs enter into carbon exchange considerations, such as leaf sheaths, roots, ears, and tassels. The distinction between photosynthesis and respiration processes is clear in terms of substrates, but becomes blurred in terms of biochemical energy supply since both processes may be occurring in the same leaf cells. Since respiration in the light may be different from respiration in the dark (Sharp et al., 1984; Brooks \& Farquhar, 1985), the approach of deWit (1978) seems desirable. deWit's approach 
uses $\mathrm{CO}_{2}$ exchange measurements during day and night hours to estimate net carbon exchange of leaves, and considers the growth and maintenance requirements of nonphotosynthesizing organs separately. Another approach would estimate gross photosynthesis of leaves and then consider leaf growth and maintenance requirements by methods similar to those used for nonphotosynthesizing organs, but perhaps with different coefficients (Baker et al., 1972). Measurements of stand photosynthesis with canopy enclosures often are confounded by soil $\mathrm{CO}_{2}$ evolution. Therefore, measurements in the light are followed immediately with measurements in a darkened chamber to obtain an estimate of gross canopy photosynthetic rate. This is valid to the extent that respiration in the dark is equal to respiration in the light, which may be true for $\mathrm{C} 4$ plants like corn. Obviously, a perfect separation of photosynthesis and respiration gas exchanges is very difficult. The best methods may depend on how one plans to use measurements to verify any particular model.

Considering the detailed carbon budget for an entire season, as $\mathrm{McCree}$ (1988) did for sorghum, is beyond the scope of this chapter; therefore, let us consider a corn plant just prior to tasseling so that vegetative components dominate. Based on data for corn from Foth (1962), deWit (1978), Yao (1980), and Righes (1980), a typical stand just prior to tasseling in the USA Corn Belt might have the characteristics shown in Table 7-2. The final seasonal grain yield for this typical corn stand might be $1 \mathrm{~kg} \mathrm{~m}^{-2}(175 \mathrm{bu}$ acre $^{-1}$ ).

For the purpose of this chapter, we will assume that corn leaves are not growing, which is valid just prior to tasseling. We further assume that the net photosynthesis and nighttime respiration relations given in Fig. 7-2 will represent the net carbon source provided by a leaf. Thus, the carbon cost of phloem loading, various carbon transformations, and maintenance respiration of leaves during the day are accommodated in the net photosynthesis relations. Maintenance respiration of leaves at night is accounted for by the dark respiration vs. temperature relation. At $25^{\circ} \mathrm{C}$ the daily dark respiration for a leaf respiration rate of $2.0 \mu \mathrm{mol} \mathrm{m}^{-2} \mathrm{~s}^{-1}$ assumed for corn compares with the daily maintenance coefficient of $0.03 \mathrm{~g}$ glucose ( $\mathrm{g}$ dry wt.) ${ }^{-1}$ $\mathrm{d}^{-1}$, which is provided by McCree (1988) for sorghum leaves, for the stand characteristics summarized in Table 7-2.

The maintenance requirements of leaf sheaths are assumed to be offset by their photosynthesis, the maintenance respiration of the stem is assumed half that of leaves (McCree, 1988), and the maintenance respiration of roots is assumed to be equal to that of leaves because of sloughing, exudation, and ion exchange (Amthor, 1984; Lambers, 1985, 1987). Much uncertainty exists about carbon lost in the root system. Measurements by Andre et al. (1978) of root respiration and exudation are consistent with this assumption of a maintenance coefficient for roots about equal to that of leaves. McCree (1988) assumed that roots had one-third the maintenance cost of leaves, which seems low. Of course these root maintenance costs decrease during grain fill. Thus, at $25^{\circ} \mathrm{C}$ the maintenance respiration of roots and stems just before tasseling would be 0.03 and $0.015 \mathrm{~g}$ glucose ( $\mathrm{g}$ dry wt.) $)^{-1} \mathrm{~d}^{-1}$ respectively 
Table 7-2. Typical characteristics of a corn stand just before tasseling in the Corn Belt, USA.

\begin{tabular}{lc}
\hline Characteristic & Value and unit of measurement \\
\hline Planting density & $6 \mathrm{plants} \mathrm{m}^{-2}$ \\
Height & $2.0 \mathrm{~m}$ \\
Row spacing & $0.76 \mathrm{~m}$ \\
Leaf area index (LAI) & 3.5 \\
Leaf dry weight/leaf area & $77 \mathrm{~g} \mathrm{~m}^{-2}$ \\
Dry weight/ground area: & \\
Total vegetative & $900 \mathrm{~g} \mathrm{~m}^{-2}$ \\
Leaves & $270 \mathrm{~g} \mathrm{~m}^{-2}$ \\
Sheaths & $135 \mathrm{~g} \mathrm{~m}^{-2}$ \\
Roots & $90 \mathrm{~g} \mathrm{~m}^{-2}$ \\
Stems & $405 \mathrm{~g} \mathrm{~m}^{-2}$ \\
\hline
\end{tabular}

with a $\mathrm{Q}_{10}$ of 2.0. These maintenance coefficients for leaves, roots, and stems in units of $\mathrm{g}$ glucose ( $\mathrm{g}$ dry wt.) $)^{-1} \mathrm{~d}^{-1}$ of $0.03,0.03$, and 0.015 , respectively, are referred to as Case $A$ in Table 7-7, and represent large coefficients for maintenance respiration. A second example representing lower maintenance requirements uses a nighttime leaf dark respiration rate of 1.4 $\mu \mathrm{mol} \mathrm{CO}_{2} \mathrm{~m}^{-2} \mathrm{~s}^{-1}$, which agrees well with gas exchange measurements from Nebraska by the authors. From simulations, this leaf respiration rate agrees with a daily maintenance respiration coefficient of $0.02 \mathrm{~g}$ glucose $(\mathrm{g}$ dry wt.) ${ }^{-1} \mathrm{~d}^{-1}$. We assume a root maintenance coefficient one-third that of leaves (McCree, 1988) and a stem maintenance coefficient $1 / 10$ that of leaves. Thus, the lower maintenance respiration case (Case B in Table 7-7) uses maintenance coefficients for leaves, stems, and roots in units of $\mathrm{g}$ glucose (g dry wt.) ${ }^{-1} \mathrm{~d}^{-1}$ of $0.02,0.0067$, and 0.002 .

The growth respiration can be computed from the work of Penning deVries based on biochemical pathways using a consistent composition typical of corn (Vertregt \& Penning deVries, 1987). The cost of converting glucose to DM, termed the production value inverse (PVI) by Vertregt and Penning deVries (1987), permits an estimate of the DM increment that could be realized from a given amount of net photosynthesis that has had maintenance costs subtracted. For corn, the PVI is $1.42 \mathrm{~g}$ glucose (g dry wt.) (Vertregt \& Penning deVries, 1987).

\section{MODEL COMPARISONS WITH MEASUREMENTS}

The radiation model that is used in this chapter is based on several assumptions including random leaf positioning in the horizontal, azimuthal symmetry, and a well-defined leaf inclination distribution, such as spherical, conical or vertical. This kind of model has been compared with measurements from several crops of full cover and shown to perform well in both PAR (Norman et al., 1971; Norman, 1988) and NIR (Norman et al., 1971) wavelength bands.

During the summer of 1981, measurements of intercepted PAR and canopy photosynthesis were made in corn stands of varying planting densities near 
O'Neill, NE through a combined effort by Joe Ritchie (Michigan State Univ., East Lansing, MI), Dan Knievel (Penn State Univ., University Park, PA), Don Reicosky (Univ. of Minnesota, Morris, MN), and John Norman (Univ. of Nebraska, Lincoln, NE) (1981, unpublished data). The planting densities varied from 2.3 to 7.4 plants $\mathrm{m}^{2}$, the leaf area index (LAI) varied from about 1.3 to 3.7, and the date of measurement was 4 August. The measured LUE was $6.9 \mathrm{~g} \mathrm{CO}_{2}$ (MJ IPAR) $^{-1}$. This LUE is in good agreement with the results of the Cupid model, which averaged $6.8 \mathrm{~g} \mathrm{CO}_{2}$ (MJ IPAR) $^{-1}$ over 17 instantaneous periods that correspond to chamber measurements at the three LAIs of 1.3, 2.2, and 3.7.

\section{REVIEW OF LIGHT-USE EFFICIENCY MEASUREMENTS}

Measurements of PAR intercepted by a canopy and canopy photosynthesis can be used to estimaste short-term (minutes to hours) canopy LUE. Care must be taken to eliminate soil respiration. Chambers can also be used to estimate $\mathrm{CO}_{2}$ LUE over longer periods of days, weeks, or even months. Measurements of IPAR and DM over longer periods can be used to estimate DM LUE. We will limit this discussion to canopies of full cover (LAI > 3).

Jones et al. (1986) measured intercepted PAR and canopy (including soil) carbon exchange rates on corn at $50 \%$ silking and $6 \mathrm{~d}$ later. Assuming a soil respiration rate of $4 \mu \mathrm{mol} \mathrm{CO}_{2} \mathrm{~m}^{-2} \mathrm{~s}^{-1}$, at solar noon the LUE was 8.1 and $5.7 \mathrm{~g} \mathrm{CO}_{2}$ (MJ IPAR) $^{-1}$ respectively. These values approach predictions from Cupid presented in the next section.

Jones et al. (1985a) measured soybean canopy LUEs in outdoor controlled-environment chambers at Growth Stages R4 and R5 about 60 to $80 \mathrm{~d}$ after planting. The average daytime LUEs were about $6.0 \mathrm{~g} \mathrm{CO}_{2}(\mathrm{MJ}$ PAR) ${ }^{-1}$ for the LAI of 3.3. Jones et al. (1985b) determined a seasonal LUE of about $5.0 \mathrm{~g} \mathrm{CO}_{2}$ (MJ IPAR) $^{-1}$ on soybean. Jones et al. (1987, unpublished data) provided unpublished data on tomato for plants grown in outdoor chambers at two nighttime temperatures. The LUE was $6.2 \mathrm{~g} \mathrm{CO}_{2}(\mathrm{MJ}$ IPAR) ${ }^{-1}$ for a $20^{\circ} \mathrm{C}$ night temperature and $5.6 \mathrm{~g} \mathrm{CO}_{2}$ (MJ IPAR) $^{-1}$ for a $12^{\circ} \mathrm{C}$ night temperature.

The LUE was measured for a wheat canopy near midday about 40 to $70 \mathrm{~d}$ after sowing when the LAI was between 3.5 and 5.0 (Puckridge \& Ratkowsky, 1971). After correcting for soil respiration, the $\mathrm{LUE}=4.2 \mathrm{~g} \mathrm{CO}_{2}$ (MJ IPAR) $^{-1}$ for an incident PAR of $1600 \mu \mathrm{mol}$ photons $\mathrm{m}^{-1} \mathrm{~s}^{-1}$. At incident PAR of 640 and $320 \mu \mathrm{mol}$ photons $\mathrm{m}^{-2} \mathrm{~s}^{-1}$, the LUE was 6.3 and

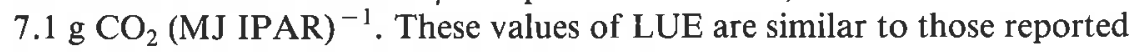
for soybean. Spiertz and van deHaar (1978) also reported a midday LUE of $4.7 \mathrm{~g} \mathrm{CO}_{2}$ (MJ IPAR) $^{-1}$ for wheat about $1 \mathrm{wk}$ after anthesis (23 June), with $\mathrm{LAI} \approx 4$ and incident $\mathrm{PAR}=1800 \mu \mathrm{mol}$ photons $\mathrm{m}^{-2} \mathrm{~s}^{-1}$. Their LUE was 6.9 and $7.1 \mathrm{~g} \mathrm{CO}_{2}$ (MJ IPAR) ${ }^{-1}$ at 700 and $350 \mu \mathrm{mol}$ photons $\mathrm{m}^{-2} \mathrm{~s}^{-1}$ incident PAR. The daily LUE from Spiertz and van deHaar (1978) was $4.7 \mathrm{~g} \mathrm{CO}_{2}$ (MJ IPAR) $^{-1}$ for 23 June, which had a total incident solar radiation of $22 \mathrm{MJ} \mathrm{m}^{-2}$. The measurements made by Spiertz and van de- 
Haar (1978) during the week surrounding 23 June can be used to estimate an average LUE of $2.2 \mathrm{~g}$ DMAG (MJ IPAR) ${ }^{-1}$; this DM value is $47 \%$ of the daily $\mathrm{CO}_{2}$ LUE.

Estimates of DM LUE vary between 2.9 (Williams et al., 1965), 3.2 (Yao, 1980), 3.8 (Sivakumar \& Virmani, 1984), and 4.4 g DMAG (MJ IPAR) ${ }^{-1}$ (Griffin, 1980) for corn grown under field conditions. This is a wide range of values and a clearer understanding of the reason for this range would be most useful. Light-use efficiency estimates for sorghum are similar; 2.4 (Muchow \& Coates, 1986), 2.9 (Sivakumar \& Virmani, 1984), and $3.0 \mathrm{~g}$ DMAG (MJ IPAR) ${ }^{-1}$ (Steiner, 1986).

Hesketh and Baker (1967) suggested many years ago that canopy LUE may be a relatively constant quantity based on literature data for corn and cotton. The data on corn that they cited from Baker and Musgrave (1964) indicated $3.0 \mathrm{~g} \mathrm{CO}_{2}$ (MJ ISR) ${ }^{-1}$. However, the in-canopy light sensor was not a solarimeter and, even though they tried to correct for wavelength peculiarities, the LUE probably is more appropriately expressed as $6.4 \mathrm{~g}$ $\mathrm{CO}_{2}$ (MJ IPAR) ${ }^{-1}$. Because of the light sensor used, Baker and Musgrave's (1964) LUE should be between the model values for IPAR ( $\sim \mathrm{g} \mathrm{CO}_{2}$ $\left.\mathrm{MJ}^{-1}\right)$ and ISR $\left(\sim 4 \mathrm{~g} \mathrm{CO}_{2} \mathrm{MJ}^{-1}\right)$.

\section{INTERPRETATIONS FROM THE CUPID MODEL}

The plant-environment model Cupid provides a means for studying the characteristics of crop LUE. Using hourly solar radiation and weather data, along with various soil and plant characteristics (Norman \& Campbell, 1983), hourly canopy photosynthesis and radiation penetration are predicted with Cupid.

The simulations from Cupid are based on $8 \mathrm{~d}$ of hourly solar radiation and weather data collected over corn at Garden City, KS by J. Steiner and E.T. Kanemasu of Kansas State Univ. (1981, unpublished data). They also measured the LAI (2.8) and crop height $(2 \mathrm{~m})$. Table 7-3 summarizes the

Table 7-3. Daily summary of solar radiation, air temperature, air vapor pressure, and mean wind speed for the $8 \mathrm{~d}$ used in simulations.

\begin{tabular}{|c|c|c|c|c|c|c|}
\hline \multirow{2}{*}{$\begin{array}{l}\text { Day } \\
\text { no. }\end{array}$} & \multirow{2}{*}{$\begin{array}{c}\text { Solar } \\
\text { radiation }\end{array}$} & \multicolumn{3}{|c|}{ Air temperature } & \multirow{2}{*}{$\begin{array}{l}\text { Vapor } \\
\text { pressure }\end{array}$} & \multirow{2}{*}{$\begin{array}{l}\text { Wind } \\
\text { speed }\end{array}$} \\
\hline & & Mean & Maximum & Minimum & & \\
\hline & MJ & $\longrightarrow$ & $-{ }^{\circ} \mathrm{C}$ & 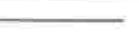 & $\mathrm{KPa}$ & $\mathrm{m} \mathrm{s}^{-1}$ \\
\hline 201 & 29.7 & 27.5 & 35.0 & 18.2 & 2.25 & 2.0 \\
\hline 202 & 29.6 & 28.0 & 37.5 & 21.2 & 2.32 & 3.2 \\
\hline 203 & 14.1 & 22.1 & 26.1 & 18.4 & 2.24 & 2.6 \\
\hline 204 & 23.4 & 26.6 & 33.4 & 19.9 & 2.32 & 2.0 \\
\hline 205 & 19.5 & 27.6 & 35.5 & 22.3 & 2.24 & 2.5 \\
\hline 206 & 21.0 & 23.7 & 29.9 & 17.8 & 2.27 & 1.7 \\
\hline 207 & 15.3 & 21.9 & 25.5 & 19.2 & 2.39 & 2.3 \\
\hline 208 & 16.9 & 21.8 & 27.8 & 17.8 & 2.20 & 2.2 \\
\hline
\end{tabular}


solar radiation and weather data for the $8 \mathrm{~d}$. These $8 \mathrm{~d}$ represent a wide range of radiation and temperature conditions typical of the corn belt in the central USA.

The LUEs of a C4 crop (typical of corn) and a C3 crop (typical of soybean) were calculated hour-by-hour with Cupid for each of the $8 \mathrm{~d}$. The corn canopy was assumed to have a spherical leaf-angle distribution. We will use the symbolism.

$$
\mathrm{Q}\left(\mathrm{CO}_{2}, \mathrm{IPAR}\right)=\mathrm{LUE}
$$

where the quantities in parentheses refer to the basis for the efficiency definition. The values for $\mathrm{Q}\left(\mathrm{CO}_{2}, \mathrm{IPAR}\right)$ include daytime photosynthesis plus nighttime dark respiration. This is the sum of measurements made over the canopy with a leaf gas exchange system. The hourly values of $\mathrm{Q}\left(\mathrm{CO}_{2}\right.$, IPAR) varied from about 6 to $10 \mathrm{~g} \mathrm{CO}_{2}$ (MJ IPAR) $^{-1}$ for corn and 4 to $12 \mathrm{~g} \mathrm{CO}_{2}$ (MJ IPAR) ${ }^{-1}$ for soybean (Fig. 7-3). The upper values for soybean, which occur only in the early morning hours, are close to the photochemical efficiency of about $12 \mathrm{~g}$ (MJ APAR) ${ }^{-1}$. Clearly, many factors can affect both light penetration and canopy photosynthesis on an hourly basis. One factor that appears to be causing variation in canopy LUE is the fraction of radiation above the canopy in the form of direct beam (Fig. 7-3). When the radiation above the canopy is mainly diffuse, the canopy LUE

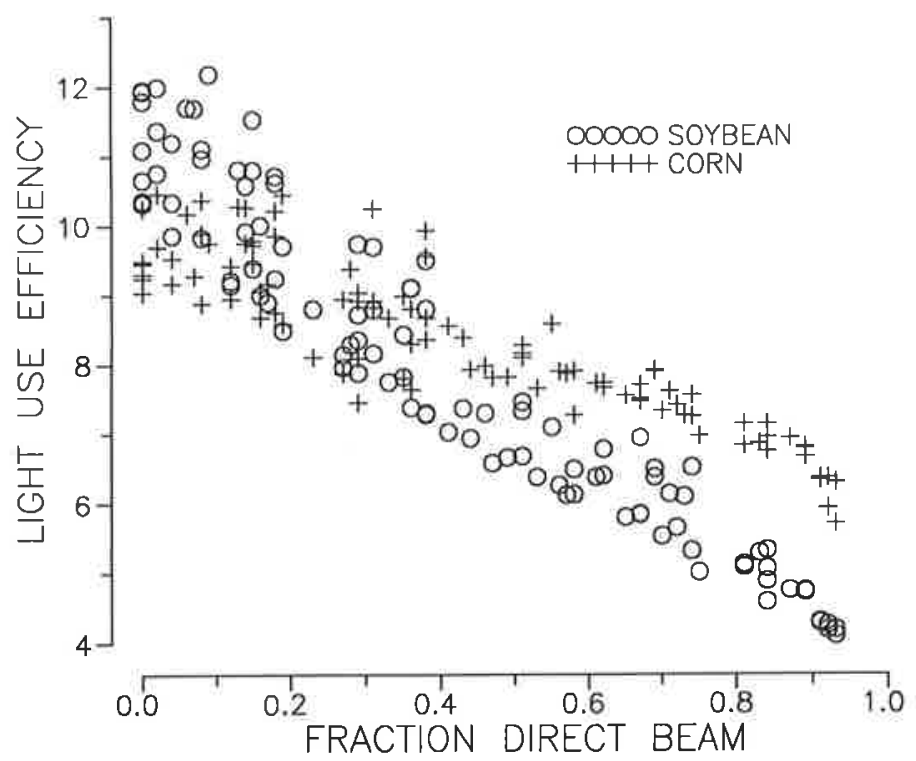

Fig. 7-3. The dependence of predicted light-use efficiency $\left[\mathrm{g} \mathrm{CO}_{2}(\mathrm{MJ} \text { IPAR })^{-1}\right]$ on the fraction of photosynthetically active radiation above the canopy that is from a direct beam. The canopy light-use efficiency is based on intercepted PAR and results are for C3 (o) and C4 (+) canopies. 
is larger. This occurs because diffuse light is more uniformly and efficiently distributed over a canopy of leaves that may saturate at high light intensities. When the radiation incident on a canopy is diffuse, the illumination levels usually are low, so that the quantity of intercepted radiation is low even though the LUE may be high. The daily LUE is calculated from the ratio of daily net photosynthesis and daily IPAR. Obviously, the daily LUE should not be calculated from an average of the hourly LUEs. The results in Fig. 7-3 incorporate many factors besides the fraction of beam radiation above the canopy (e.g., temperature, sun zenith angle, vapor pressure deficit, and magnitude of the incident radiation). However, from various tests the dominant factor is the fraction of diffuse radiation.

The daily LUEs do not vary as much as the hourly values do. The average of the eight daily LUEs for soybean are about $85 \%$ those of corn (Table $7-4)$. On overcast days the LUE of corn and soybean are similar, and soybean may have greater efficiency on cool days. On clear, hot days the LUE of soybean is about three-quarters that of corn. Apparently the occurrence of two clear, three overcast, and three partly cloudy days resulted in greater LUEs for corn than soybean. However, if leaf characteristics did not change, we would expect corn to be more efficient in predominantly clear, warm climates and soybean more efficient in cloudy, cool climates. Both C3 and C4 plant types adapt to their radiation environments, so such simple-mined statements may not hold. To simulate adaptation, Cupid simulations assumed that photosynthetic rate was independent of temperature (dark respiration remained temperature dependent) and near the maximum rate of $30^{\circ} \mathrm{C}$ for $\mathrm{C} 3$ and $35^{\circ} \mathrm{C}$ for $\mathrm{C} 4$ canopies (Table 7-5). With this assumption, LUEs increased about 5 to $10 \%$.

The conversion factors between absorbed or intercepted, PAR or SR can be confusing. Values for all four combinations are included in Table 7-4. Gallagher and Biscoe (1978) estimated the fraction of PAR absorbed from the fraction of solar radiation transmitted. Their Eq. [A.3] yields absorbed PAR fractions that are smaller than those obtained from the Cupid model, assuming the ISR is given. If LAI is varied from 1.5 to 5 , under a range of incident radiation conditions, the APAR fraction of Gallagher and

Table 7-4. Predicted mean and standard deviation (in parentheses) of eight daily lightuse efficiencies for typical C3 and C4 canopies at several leaf area indices using measured weather data summarized in Table 2.

\begin{tabular}{lccccc}
\hline Canopy & $\mathrm{LAI}$ & $\mathrm{Q}\left(\mathrm{CO}_{2}, \mathrm{IPA}\right) \dagger$ & $\mathrm{Q}\left(\mathrm{CO}_{2}, \mathrm{APAR}\right) \dagger$ & $\mathrm{Q}\left(\mathrm{CO}_{2}, \mathrm{ISR}\right) \S$ & $\mathrm{Q}\left(\mathrm{CO}_{2}, \mathrm{ASR}\right) \uparrow$ \\
\hline $\mathrm{C} 4$ & 1 & $7.6(0.4)$ & $7.7(0.4)$ & $4.7(0.2)$ & $5.8(0.3)$ \\
(Corn) & 3 & $7.5(0.5)$ & $7.8(0.5)$ & $4.2(0.3)$ & $5.3(0.4)$ \\
& 5 & $7.2(0.5)$ & $7.5(0.5)$ & $3.7(0.2)$ & $4.8(0.3)$ \\
$\mathrm{C} 3$ & 1 & $6.5(0.8)$ & $6.6(0.9)$ & $4.1(0.5)$ & $5.0(0.7)$ \\
(Soybean & 3 & $6.5(1.0)$ & $6.7(1.0)$ & $3.6(0.5)$ & $4.6(0.7)$ \\
or wheat) & 5 & $6.2(1.0)$ & $6.5(1.1)$ & $3.2(0.5)$ & $4.2(0.7)$ \\
\hline
\end{tabular}

$\dagger$ IPAR represents intercepted photosynthetically active radiation.

$\ddagger$ APAR represents absorbed photosynthetically active radiation.

$\S$ ISA represents intercepted solar radiation.

I ASR represents absorbed solar radiation. 
Table 7-5. Mean and standard deviation (in parentheses) of eight daily light-use efficiencies predicted from Cupid for typical C3 and C4 canopies assuming that leaf photosynthetic rate is independent of temperature. The same input data were used as in Table 4.

\begin{tabular}{lcc}
\hline Canopy & LAI & $\mathrm{Q}\left(\mathrm{CO}_{2}, \mathrm{IPAR}\right) \dagger$ \\
\hline C4 & 1 & $8.2(0.5)$ \\
(Corn) & 3 & $8.0(0.6)$ \\
& 5 & $7.7(0.6)$ \\
C3 & 1 & $6.4(0.7)$ \\
(Soybean & 3 & $6.3(0.8)$ \\
or wheat) & 5 & $6.0(0.8)$ \\
\hline
\end{tabular}

† IPAR represents intercepted photosynthetically active radiation.

Table 7-6. The ratios of various combinations of absorbed (A) or intercepted (I), photosynthetically active radiation (PAR) or solar radiation (SR).

\begin{tabular}{lccc}
\hline & \multicolumn{3}{c}{ Leaf area index } \\
\cline { 2 - 4 } Ratio & 1.5 & 2.8 & 5.0 \\
\hline IPAR/APAR & 1.03 & 1.04 & 1.05 \\
IPAR/ISR & 0.60 & 0.56 & 0.51 \\
IPAR/ASR & 0.75 & 0.71 & 0.66 \\
\hline
\end{tabular}

$\dagger$ Light-use efficiency in $\mathrm{g} \mathrm{CO}_{2}$ (MJ IPAR) $^{-1}$ would be multiplied by the number in the table to correct it to another radiation base. For example $8.0 \mathrm{~g} \mathrm{CO}_{2}(\mathrm{MJ} \mathrm{IPAR})^{-1}$ is equivalent to $4.8 \mathrm{~g} \mathrm{CO}_{2}$ (MJ ISR) $^{-1}$ at a leaf area index of 1.5 .

Biscoe (1978) varies from 0.67 to 0.97 , assuming a spherical leaf-angle distribution and a mean sun incidence angle of $45^{\circ}$ in their Eq. [A.4]. Results from Cupid vary from 0.64 to 0.95 ; thus the Gallagher and Biscoe (1978) Eq. [4] appears to be quite reasonable if ISR is calculated from exponential extinction. If the ISR values calculated from Cupid are used in the Gallagher and Biscoe (1978) Eq. [A.3], the resultant predicted values of APAR vary from 0.53 to 0.83 . Thus, results from Cupid suggest that APAR values estimated using their Eq. [A.3] and measured values of ISR with solarimeters should be increased by a factor of 1.25 for a LAI of about 1.5 to a factor of 1.15 for a LAI of about 5 . The ratios of various combinations of absorbed or intercepted, PAR or SR are shown in Table 7-6.

The values of LUE in Tables 7-4 and 7-5 are in reasonable agreement with literature values discussed earlier based on $\mathrm{CO}_{2}$ exchange. However, establishing a common basis for comparison is not easy because of some uncertainty in how maintenance and growth respiration should be accommodated. Because of these difficulties, we will only convert the $\mathrm{CO}_{2} \mathrm{LUE}$ to DM for the corn characteristics given in Table 7-2. The various components of the carbon balance of this corn canopy near tasseling are given in Table 7-7. The final DM LUE of $2.5 \mathrm{~g} \mathrm{DM} \mathrm{MJ}^{-1}$ for Case $\mathrm{A}$ is lower than values measured for corn and summarized earlier. The value of $3.2 \mathrm{~g} \mathrm{DM} \mathrm{MJ}^{-1}$ for Case B with lower maintenance respiration values is more typical of measured LUEs, which typically vary between 3 and $4 \mathrm{~g} \mathrm{DM} \mathrm{MJ}^{-1}$. 
Table 7-7. Mean daily carbon exchanges for the corn canopy described in Table 7-2.

\begin{tabular}{|c|c|c|}
\hline & \multicolumn{2}{|c|}{ Canopy carbon exchange } \\
\hline & Case A & Case B \\
\hline & $-\mathrm{g} \mathrm{CO}$ & ${ }^{-2} \mathrm{~d}^{-1}$ \\
\hline \multicolumn{3}{|l|}{ Photosynthesis } \\
\hline Gross minus leaf respiration & $73.7(14.0)$ & $73.7(14.0)$ \\
\hline Net (Gross minus total maintenance) & $\begin{array}{l}61.9(12.0) \\
49.6(11.0)\end{array}$ & $\begin{array}{l}65.8(12.7) \\
63.8(12.5)\end{array}$ \\
\hline \multicolumn{3}{|l|}{ Maintenance respiration } \\
\hline Stem & $8.8(1.4)$ & $1.2(0.2)$ \\
\hline Leaf & $11.8(1.9)$ & $7.9(1.3)$ \\
\hline Root & $3.5(0.2)$ & $0.8(0.1)$ \\
\hline Grain & & \\
\hline Total & $24.1(2.4)$ & $9.9(1.3)$ \\
\hline Growth respiration & $10.0(2.1)$ & $12.0(2.3)$ \\
\hline Dry matter increment (g DM m$\left.{ }^{-2} \mathrm{~d}^{-1}\right)$ & $22.6(5.1)$ & $29.2(5.7)$ \\
\hline IPAR $+\left(\mathrm{MJ} \mathrm{m}^{-2} \mathrm{~d}^{-1}\right)$ & $9.0(2.4)$ & $9.0(2.4)$ \\
\hline Light-use efficiency $\left(\mathrm{CO}_{2}, \mathrm{PAR}\right)$ & $6.9 \mathrm{~g} \mathrm{CO}_{2} \mathrm{MJ}^{-1}$ & $7.1 \mathrm{~g} \mathrm{CO}_{2} \mathrm{MJ}^{-1}$ \\
\hline Light-use efficiency (DM, PAR) & $2.5 \mathrm{~g} \mathrm{DM} \mathrm{MJ}^{-1}$ & $3.2 \mathrm{~g} \mathrm{DM} \mathrm{MJ}^{-1}$ \\
\hline
\end{tabular}

$\uparrow I P A R$ represents intercepted photosynthetically active radiation.

\section{SUMMARY}

The plant-environment model Cupid is useful in studying canopy LUE by combining knowledge of leaf physiological and radiative properties with canopy architecture. Hourly canopy LUEs vary more than daily values, especially for $\mathrm{C} 3$ crops. Measured and modeled short-term $(<1 \mathrm{~h})$ canopy LUEs agree well at values near $6.5 \mathrm{~g} \mathrm{CO}_{2}$ (MJ IPAR) $^{-1}$ for corn. A modeled value of canopy LUE over a week, based on DM, is sensitive to choice of maintenance respiration coefficients. A $25 \%$ difference resulted between two reasonable choices of coefficients from the literature.

Cupid has been used to predict conversion factors among intercepted or absorbed, SR or PAR. These may be useful for resolving the many ways that canopy LUEs are expressed in the literature.

The canopy LUE can vary with environmental conditions (radiation and temperature), leaf area index, and maintenance and growth respiration. Maintenance respiration coefficients are difficult to measure and are known to vary among cultivars of a single species. These variations in maintenance respiration are not likely to be accommodated indirectly using only a LUE to estimate DM increment from intercepted light. Dry matter LUE coefficients should be used with caution in simple models because of the potential for systematic errors. Furthermore, use of such coefficients may obscure possibilities for increased productivity by reductions in maintenance respiration.

\section{REFERENCES}

Amthor, J.S. 1984. The role of maintenance respiration in plant growth. Plant Cell Environ. 7:561-569.

Andre, M., D. Massimino, and A. Daguenet. 1978. Daily patterns under the life cycle of a maize crop. II. Mineral nutrition, root respiration and root excretion. Physiol. Plant 44:197-204. 
Baker, D.N., J.D. Hesketh, and W.G. Duncan. 1972. Simulation of growth and yield in cotton: I. Gross photosynthesis, respiration and growth. Crop Sci. 12:431-439.

Baker, D., and R. Musgrave. 1964. Photosynthesis under field conditions. V. Further plant chamber studies of the effects of light on corn. Crop Sci. 4:127-131.

Ball, J.T., I.E. Woodrow, and J.A. Berry. 1986. A model predicting stomatal conductance and its contribution to the control of photosynthesis under different environmental conditions. p. 221-224. In J. Biggins (ed.) Progress in photosynthesis research, Vol. 4. Martinus Nijhoff Publ., Dordrecht, Netherlands.

Brooks, A., and G.D. Farquhar. 1985. Effect of temperature on the $\mathrm{CO}_{2} / \mathrm{O}_{2}$ specificity of ribulose-1,5-bisphosphate carboxylase/oxygenase and the rate of respiration in the light. Planta 165:397-406.

Charles-Edwards, D.A. 1981. Physiological determinents of crop growth. Academic Press, New York.

Chmora, S.N., and V.M. Oya. 1967. Photosynthesis in leaves as a function of temperature. Sov. Plant Physiol. (Engl. Transl.) 14:513-519.

deWit, C.T. 1978. Simulation of assimilation, respiration and transpiration of crops. John Wiley \& Sons, New York.

Edmeades, G.O., and T.B. Daynard. 1979. The relationship between yield and photosynthesis at flowering in individual maize plants. Can. J. Plant Sci. 59:585-601.

Farquhar, G.D., and S. von Caemmerer. 1982. Modeling of photosynthetic response to environmental conditions. p. 549-588. In O.L. Lange et al. (ed.) Physiological plant ecology II. Encyclopedia of plant physiology. New ser. vol. 12B. Springer-Verlag, Berlin.

Foth, H.D. 1962. Root and top growth of corn. Agron. J. 54:49-52.

Gallagher, J.N., and P.V. Biscoe. 1978. Radiation absorption, growth and yield of cereals. J. Agric. Sci. (Cambridge) 91:47-60.

Griffin, J.L. 1980. Quantification of the effects of water stress on corn growth and yield. M.S. thesis. Univ. of Missouri, Columbia.

Hesketh, J., and D. Baker. 1967. Light and carbon assimilation by plant communities. Crop Sci. 7:285-293.

Jones, J.W., B. Zur, and J.M. Bennett. 1986. Interactive effects of water and nitrogen stresses on carbon and water vapor exchange of corn canopies. Agric. For. Meteorol. 38:113-126.

Jones, P., L.H. Allen, Jr., and J.W. Jones. 1985a. Responses of soybean canopy photosynthesis and transpiration to whole-day temperature changes in different $\mathrm{CO}_{2}$ environments. Agron. J. 77:242-249.

Jones, P., J.W. Jones, and L.H. Allen, Jr. 1985b. Seasonal carbon and water balances of soybeans grown under stress treatments in sunlit chambers. Trans. ASAE 28:2021-2028.

Lambers, H. 1985. Respiration in intact plants and tissues: Its regulation and dependence on environmental factors, metabolism and invaded organisms. p. 418-473. In R. Douce and D.A. Day (ed.) Encyclopedia of plant physiology, Vol. 18. Springer-Verlag, Berlin, West Germany.

Lambers, H. 1987. Growth, respiration, exudation and symbiotic associations: The fate of carbon translocated to the roots. p. 125-145. In P.J. Gregory, J.V. Lake, and D.A. Rose (ed.) Root development and function. Cambridge Univ. Press, Cambridge, England.

Losch, R., and J.D. Tenhunen. 1981. Stomatal responses to humidity-phenomenon and mechanism. p. 137-161. In P.G. Jarvis and T.A. Mansfield (ed.) Stomatal physiology. Cambridge Univ. Press, Cambridge, England.

McCree, K.J. 1988. Sensitivity of sorghum grain yield to ontogenetic changes in respiration coefficients. Crop Sci. 28:114-120.

McDermitt, D.K., and R.S. Loomis. 1981. Elemental composition of biomass and its relation to energy content, growth efficiency and growth yield. Ann. Bot, 48:275-290.

Monteith, J.L. 1977. Climate and the efficiency of crop production in Britain. Philos. Trans. R. Soc. London B. 281:277-294.

Monteith, J.L. 1981. Climate variation and the growth of crops. Q.J.R. Meteorol. Soc. 107:749-774.

Muchow, R.C., and D.B. Coates. 1986. An analysis of the environmental limitations to yield of irrigated grain sorghum during the dry season in tropical Australia using a radiation interception model. Aust. J. Agric. Res. 37:135-148.

Nilson, T. 1971. A theoretical analysis of the frequency of gaps in plant stands. Agric. Meteorol. $8: 25-38$. 
Norman, J.M. 1979. Modeling the complete crop canopy. p. 249-277. In B.J. Barfield and J. Gerber (ed.) Modification of the aerial environment of crops. Am. Soc. Agric. Eng., St. Joseph, MI.

Norman, J.M. 1986. Instrumentation use in a comprehensive description of plant-environment interactions. p. 149-307. In W. Gensler (ed.) Advanced agricultural instrumentation. Martinus Nijhof Publ., Dordrecht, Netherlands.

Norman, J.M. 1988. Synthesis of canopy processes. p. 161-175. In G. Russell, B. Marshall, and P.G. Jarvis (ed.) Plant canopies: Their growth, form and function. Cambridge Univ. Press, Cambridge, England.

Norman, J.M., and G.S. Campbell. 1983. Application of a plant-environment model to problems in irrigation. p. 155-188. In D.I. Hillel (ed.) Advances in irrigation. Academic Press, New York.

Norman, J.M., E.E. Miller, and C.B. Tanner. 1971. Light intensity and sunfleck size distributions in plant canopies. Agron. J. 63:743-748.

Penning deVries, F.W.T., A.H.M. Brunsting, and H.H. van Laar. 1974. Products, requirements and efficiency of biosynthesis: a quantitative approach. J. Theor. Biol. 45:339-377.

Puckridge, D.W., and D.A. Ratkowski. 1971. Photosynthesis of wheat under field conditions: IV. The influence of density and leaf area index on the response to radiation. Aust. J. Agric. Res. 22:11-20.

Righes, A.A. 1980. Water uptake and root distribution of soybeans, grain sorghum and corn. M.S. thesis. Iowa State Univ., Ames.

Schoolfield, R.M., P.J.H. Sharp, and C.E. Magnuson. 1981. Non-linear regression of biological temperature-dependent rate models based on absolute reaction-rate theory. J. Theor. Biol. 88:719-731.

Schulze, E.D., N.C. Turner, T. Gollan, and A. Shackel. 1987. Stomatal responses to air humidity and to soil drought. p. 311-321. In E. Zeiger, G.D. Farquhar, and I.R. Cowan (ed.) Stomatal function. Stanford Univ. Press, Stanford, CA.

Sharp, R.E., M.A. Matthews, and J.S. Boyer. 1984. Kok effect and the quantum yield of photosynthesis. Plant Physiol. 75:95-101.

Sivakumar, M.V.K., and S.M. Virmani. 1984. Crop productivity in relation to interception of photosynthetically active radiation. Agric. For. Meteorol. 31:131-141.

Spiertz, J.H.J., and H. van DeHaar. 1978. Differences in grain growth, crop photosynthesis and distribution of assimilates between semi-dwarf and a standard cultivar of wheat. Neth. J. Agric. Sci. 26:233-249.

Steiner, J.L. 1986. Dryland grain sorghum water use, light interception and growth responses to planting geometry. Agron. J. 78:720-726.

Unsworth, M.H., V.M. Lesser, and A.S. Heagle. 1984. Radiation interception and the growth of soybeans exposed to ozone in open-top field chambers. J. Appl. Ecol, 21:1059-1079.

Vertregt, N., and F.W.T. Penning deVries. 1987. A rapid method for determining the efficiency of biosynthesis of plant biomass. J. Theor. Biol. 128:109-119.

Vietor, D.M., R.P. Ariyanayagam, and R.B. Musgrave. 1977. Photosynthetic selection of Zea mays L. I. Plant age and leaf position effects and a relationship between leaf and canopy rates. Crop Sci. 17:567-573.

von Caemmerer, S., and G.D. Farquhar. 1981. Some relationships between the biochemistry of photosynthesis and the gas exchange of leaves. Planta 153:367-387.

Walter-Shea, E.A. 1987. Laboratory and field measurements of leaf spectral properties and canopy architecture and their effects on canopy reflectance. Ph.D. diss. Univ. of Nebraska, Lincoln (Diss. Abstr. 87-17268).

Williams, W.A., R.S. Loomis, and C.R. Lepley. 1965. Vegetative growth of corn as affected by population density. I. Productivity in relation to interception of solar radiation. Crop Sci. 5:211-215,

Yao, N.R. 1980. Vegetative and reproductive development of corn at four spring planting dates. M.S. thesis. Penn State Univ., University Park. 
